\title{
Catch rates and distribution pattern of the silky shark, Carcharhinus falciformis, caught by the Taiwanese large-scale longline fishery in the Indian Ocean
}

Chia Yun Li

National Sun Yat-sen University, Department of Marine Biotechnology and Resources, Kaohsiung, Taiwan

Xing-Han Wu

National Sun Yat-sen University, Department of Oceanography, Kaohsiung, Taiwan

Shang Yin Vanson Liu

National Sun Yat-sen University, Department of Marine Biotechnology and Resources, Kaohsiung, Taiwan

Sheng-Ping Wang

Department of Environmental Biology and Fisheries Science, National Taiwan Ocean University, Keelung, Taiwan

Wen-Pei Tsai

National Kaohsiung University of Science and Technology, Department of Fisheries Production and Management, Kaohsiung, Taiwan, wptsai@nkust.edu.tw

Follow this and additional works at: https://jmstt.ntou.edu.tw/journal

Part of the Fresh Water Studies Commons, Marine Biology Commons, Ocean Engineering Commons, Oceanography Commons, and the Other Oceanography and Atmospheric Sciences and Meteorology Commons

\section{Recommended Citation}

Li, Chia Yun; Wu, Xing-Han; Vanson Liu, Shang Yin; Wang, Sheng-Ping; and Tsai, Wen-Pei (2021) "Catch rates and distribution pattern of the silky shark, Carcharhinus falciformis, caught by the Taiwanese large-scale longline fishery in the Indian Ocean," Journal of Marine Science and Technology. Vol. 29: Iss. 5, Article 8.

DOI: $10.51400 / 2709-6998.2468$

Available at: https://jmstt.ntou.edu.tw/journal/vol29/iss5/8

This Research Article is brought to you for free and open access by Journal of Marine Science and Technology. It has been accepted for inclusion in Journal of Marine Science and Technology by an authorized editor of Journal of Marine Science and Technology. 


\section{Catch rates and distribution pattern of the silky shark, Carcharhinus falciformis, caught by the Taiwanese large-scale longline fishery in the Indian Ocean}

\section{Acknowledgements}

The authors thank the Overseas Fisheries Development Council, Taiwan for providing shark catch and effort data of longline fisheries. We also thank anonymous reviewers for their helpful comments, which greatly improved this manuscript. This study was financially supported by the Fisheries Agency of Council of Agriculture of Taiwan under Contract No. 108AS-9.1.2-FA-F2 and 109AS-9.1.2-FA-F2. This manuscript was edited by Wallace Academic Editing. 


\title{
Catch Rates and Distribution Pattern of the Silky Shark, Carcharhinus falciformis, Caught by the Taiwanese Large-scale Longline Fishery in the Indian Ocean
}

\author{
Chia Yun Li ${ }^{a}$, Xing-Han $\mathrm{Wu}^{\mathrm{b}}$, Shang Yin Vanson Liu ${ }^{\mathrm{a}}$, \\ Sheng-Ping Wang ${ }^{c}$, Wen-Pei Tsai ${ }^{\mathrm{d}, *}$ \\ ${ }^{a}$ National Sun Yat-sen University, Department of Marine Biotechnology and Resources, Kaohsiung, Taiwan \\ ${ }^{\mathrm{b}}$ National Sun Yat-sen University, Department of Oceanography, Kaohsiung, Taiwan \\ ${ }^{c}$ Department of Environmental Biology and Fisheries Science, National Taiwan Ocean University, Keelung, Taiwan \\ ${ }^{\mathrm{d}}$ National Kaohsiung University of Science and Technology, Department of Fisheries Production and Management, Kaohsiung, Taiwan
}

\begin{abstract}
The silky shark, Carcharhinus falciformis, is widely distributed in tropical and temperate waters, and it is a common bycatch species for tuna longline fisheries. This study examined the distribution of and presents relative abundance indices of the silky shark in the Indian Ocean by using logbook and observer data from the Taiwanese large-scale tuna longline fishery between 2005 and 2019. Due to the high zero catch rate, a zero-inflated negative binomial (ZINB) model was used to standardize catch per unit effort. Due to a lack of detailed targeting information, the fishery strategy was identified by using cluster analysis based on catch composition and then incorporated as an explanatory variable related to the target species in the ZINB model. Size segregation was observed for males and females in the Indian Ocean. Juveniles were mostly concentrated between $10^{\circ} \mathrm{S}$ and $10^{\circ} \mathrm{N}$. Cluster analysis results revealed five fishing clusters based on catch composition that explained the variance in the ZINB models. Our integrated approach improves the understanding of spatiotemporal silky shark dynamics in the Indian Ocean and can be used to derive relative abundance indices for stock assessment and management.
\end{abstract}

Keywords: Silky shark, CPUE standardization, Indian ocean

\section{Introduction}

$\mathrm{E}$ lasmobranchs (sharks, rays, and skates) are crucial to the marine ecosystem [1,2]. These apex predators balance trophic interactions [3] and sustain the dynamics [4] of the marine community $[2,5,6]$. Changes in the abundance of top predators influence the composition of species in the food web $[1,7,8]$. Numerous studies [1,9-11] have demonstrated that reductions in the number of sharks and rays lead to a trophic cascade that affects every level of the food chain. Most elasmobranchs are considered k-selected species characterized by low fecundity, late sexual maturity, slow growth, and long lifespans [12]. Due to these characteristics, elasmobranchs are more vulnerable to overexploitation than teleost fish are. Moreover, if these species are overfished, their populations require longer recovery times $[2,4,13]$. According to the results of the International Union for Conservation of Nature (IUCN) Red List assessment [14], more than 249 elasmobranch species are threatened, and insufficient data existed to classify 487 species. Thus, one-quarter of ray and shark species are classified 
as threatened (critical, endangered, and vulnerable-VU) and data are insufficient for nearly half of the elasmobranch species [15].

The silky shark, Carcharhinus falciformis, is an oceanic shark with global distribution found between tropical and temperate areas $[16,17]$. It is a common bycatch species of longline tuna fisheries and the purse seine fishery in the open ocean [18-20]. In many regions, silky shark populations have declined dramatically over the past few decades due to pressures from fishing [21-23]. Like other elasmobranchs, the silky shark has low fecundity, late sexual maturity, and slow growth, which cause it to be vulnerable to anthropogenic activity and inhibit population recovery [18]. In 2015, the silky shark was listed as VU on the IUCN Red List [24]. In 2016, based on its population, it was listed on the Convention on International Trade in Endangered Species of Wild Fauna and Flora (CITES) Appendix II [25], indicating that the species is vulnerable. Stock assessments revealed that the silky shark population declined by $46-50 \%$ in the Atlantic Ocean between 1992 and 2009 and by 30\% in the western Indo-Pacific Ocean between 1995 and 2009 [21,23]. Therefore, retention of the silky shark is banned by International Commission for the Conservation of Atlantic Tunas (ICCAT) and Western and Central Pacific Fisheries Commission. At present, studies on the silky shark in the Indian Ocean are at the preliminary stage, and consequently, the shark's status is uncertain. The stock assessment and management and conservation actions are still inadequate [26].

Inadequate data are a common problem for shark stock assessment. Due to the low commercial value of the shark, the systemic fishery information needed for modeling is seldom available [27]. Moreover, data are often undermined by high zero catch rates $[28,29]$. Because the process of collecting fishery-independent data is often costly and difficult, most Regional Fisheries Management Organizations (RFMOs) rely heavily on catch per unit effort (CPUE) obtained from commercial fishery activity as an indicator of the relative abundance index [28]. To address this issue, the population trends of bycatch species are commonly estimated by using either delta lognormal models [30] or by using zero-inflated models [29,31,32]. However, a number of factors influence the CPUE of target or nontarget species including fishing gear, fishing strategies, and fishing operation methods. CPUE standardization is often used to reduce the effects of factors confounding the CPUE index results [33-36]. Lack of data regarding fishing strategies leads to incorrect or biased results. Therefore, cluster analysis based on catch composition is commonly used to detect changes in fishing strategies [37] and has been widely applied for CPUE standardization by certain RFMOs, such as the Indian Ocean Tuna Commission and ICCAT [38,39].

Insufficient data exist regarding the age distribution, growth, and reproductive biology of the silky shark in the Indian Ocean [40]. By using logbook data from Taiwanese vessels operating in the Indian Ocean, we examined the spatiotemporal distribution of the species and calculated its abundance indices. Both of these measures are critical for stock management in the Indian Ocean. This study used a zero-inflated negative binomial (ZINB) model to perform CPUE standardization. The Taiwanese tuna longline fishery data based on catch composition between 2005 and 2019 were clustered to examine fishing strategies and target effects. Observer data were also used to analyze the spatiotemporal distribution of sex and body length. The results derived from this study provide comprehensive information for stock assessment and management of the silky shark in the Indian Ocean.

\section{Materials and methods}

\subsection{Data collection}

Logbook and observer data from the Taiwanese large-scale tuna longline fishery (LTLL) between 2005 and 2019 were obtained from the Overseas Fisheries Development Council of the Republic of China. The logbook data of 499,981 longline operations comprising the vessel ID, operation time, operation area, number of hooks, and catches of 18 species including five major tunas, five major billfishes, three sharks, and other species were used to analyze and calculate CPUE (Table 1). The Taiwanese LTLL fishery operates across the Indian Ocean, and therefore, these fishery statistics are a primary source of information regarding the population status of pelagic sharks. This study also determined biological data for 1591 silky shark individuals obtained by an onboard observer program between 2005 and 2019. The observer data cover an average of $5.67 \%$ of all Taiwanese large-scale longline operations in the Indian Ocean and comprise operation time, operation area, and the fork length (FL) of the silky shark. Sex was also determined by examining the external sex organs.

\subsection{Spatiotemporal distribution}

Catch, effort, nominal CPUE (catch per 1000 hooks), and sex ratio were calculated, and the data 
Table 1. Summary of data analyzed for this study by year including the number of sets, total hooks, silky shark catches, and the percentage of silky shark catches among total tuna catches, billfish catches, and observer coverage for Taiwanese large-scale tuna longline vessels in the Indian Ocean from 2005 to 2019.

\begin{tabular}{lllll}
\hline Year & Set & Hooks & $\begin{array}{l}\text { Silky shark } \\
\text { catches }\end{array}$ & $\begin{array}{l}\text { observer } \\
\text { coverage rate }\end{array}$ \\
\hline 2005 & 72,205 & $229,107,476$ & 7591 & $0.83 \%$ \\
2006 & 51,782 & $165,372,576$ & 2484 & $1.21 \%$ \\
2007 & 43,926 & $140,968,756$ & 2234 & $5.55 \%$ \\
2008 & 31,729 & $102,126,017$ & 3106 & $5.61 \%$ \\
2009 & 39,921 & $128,268,580$ & 4025 & $5.47 \%$ \\
2010 & 29,856 & $97,611,849$ & 1684 & $7.65 \%$ \\
2011 & 22,418 & $72,349,298$ & 929 & $4.21 \%$ \\
2012 & 25,206 & $76,576,911$ & 1935 & $4.81 \%$ \\
2013 & 23,719 & $75,796,412$ & 3069 & $8.29 \%$ \\
2014 & 18,475 & $58,376,963$ & 3098 & $8.95 \%$ \\
2015 & 22,535 & $70,889,449$ & 206 & $5.99 \%$ \\
2016 & 31,540 & $101,456,183$ & 2320 & $5.34 \%$ \\
2017 & 29,946 & $99,221,840$ & 2228 & $6.32 \%$ \\
2018 & 28,032 & $93,060,320$ & 3245 & $7.53 \%$ \\
2019 & 28,691 & $89,907,590$ & 6123 & $7.25 \%$ \\
\hline Average & 33,332 & $106,739,348$ & 2952 & 0.06 \\
\hline
\end{tabular}

were then grouped using $5^{\circ} \times 5^{\circ}$ latitude and longitude grids. Hall et al. [34] suggested that the life history parameters of the silky shark are as follows: neonates (0-1 year): $65.98 \mathrm{~cm}$ FL; juveniles (age $>1$ but immature): $76.98-177.51 \mathrm{~cm}$ FL for females and 78.35-170.88 cm FL for males; adults (mature, females age $>15$ and males age $>13$ ): $>177.51 \mathrm{~cm}$ FL for females and $>170.88 \mathrm{~cm}$ FL for males.

The Indian Ocean was divided into four fishing areas based on the effort distribution and fishing grounds of the target species [41]: (1) Northwest Indian Ocean (north of $10^{\circ} \mathrm{S}$, east of $70^{\circ} \mathrm{E}$ ); (2) Northeast Indian Ocean (north of $10^{\circ} \mathrm{S}, 70^{\circ} \mathrm{E}-120^{\circ}$ E); (3) Southwest Indian Ocean (south of $10^{\circ} \mathrm{S}, 20^{\circ}$ $\mathrm{E}-60^{\circ} \mathrm{E}$ ); (4) Southeast Indian Ocean (south of $10^{\circ} \mathrm{S}$, $60^{\circ} \mathrm{E}-120^{\circ} \mathrm{E}$; Fig. 1). The annual length-frequency distribution by sex and fishing area was analyzed, and the catches, effort, and nominal CPUE distribution were compared by using both logbook and observer data. Estimates of the sex ratio, life stage, and length-frequency distribution were based on observer data only.

\subsection{Cluster analysis}

Cluster analysis was based on species composition from logbook data. These species were albacore (ALB), bigeye tuna (BET), yellowfin tuna (YFT), southern bluefin tuna (SBT), billfish, sharks, and others. A two-step method suggested by He et al. [37] was applied to process the numerous data sets
$(499,981$ sets). The data were aggregated by week and by set to avoid excessive noise caused by clustering operational data. The clusters were then merged with operational set-by-set data by using columns of vessel ID and operation date (year, month, and week) to identify the targeted fishing operations.

For the two-step method, nonhierarchical cluster analysis (K-means method; [42]) was first applied to group the datasets into 42 clusters based on catch composition $\left(P_{2}^{7}=42\right.$; two species can be chosen with priority from seven species). Ward's agglomerative hierarchical cluster analysis was applied to the dissimilarity matrix to calculate the squared Euclidean distances based on the mean species composition from the 42 nonhierarchical clusters. In this study, the clusters were defined as groupings such that the difference in the relative variance between groups and within group was $>50 \%$ [43].

\subsection{CPUE standardization}

The silky shark is a bycatch species of the Taiwanese LTLL fishery. As shown in Table 2, the logbook datasets contain a high proportion of zero catches $(95.67 \%$ on average), which may lead to bias during CPUE standardization. To prevent such bias, we adopted a ZINB model.

The probability distribution of a ZINB variable $Y$ is given by

(Equation (1): Binomial model; Equation (2): Count model-negative binomial, link = logit)

$\operatorname{Pr}(Y=0)=\omega+(1-\omega)(1-k \lambda)^{1 / k}$

$\operatorname{Pr}(Y>0)=(1-\omega) \frac{\Gamma(y+1 / k)}{\Gamma(y+1) \Gamma(1 / k)} \frac{(k \mu)^{y}}{(1+k \lambda)^{y+1 / k}}$

where $k$ is the negative binomial dispersion parameter; $\lambda$ is the mean of the underlying negative binomial distribution; and $\omega$ is the probability of an observation being drawn from the constant distribution that always generates zero.

To remove spatiotemporal influences, several factors were considered including 15 fishing years (2005-2019), four calendar quarters, and four fishing areas. Operational variables such as the number of hooks between floats (deep set: $\geq 15$ hooks; shallow set: $<15$ hooks) [36] and vessel size (Vessel: CT5, CT6, CT7) were also considered and incorporated into the cluster results as effects in the CPUE standardization models. All factors were considered to be categorical variables and were evaluated as explanatory variables for ZINBs. 


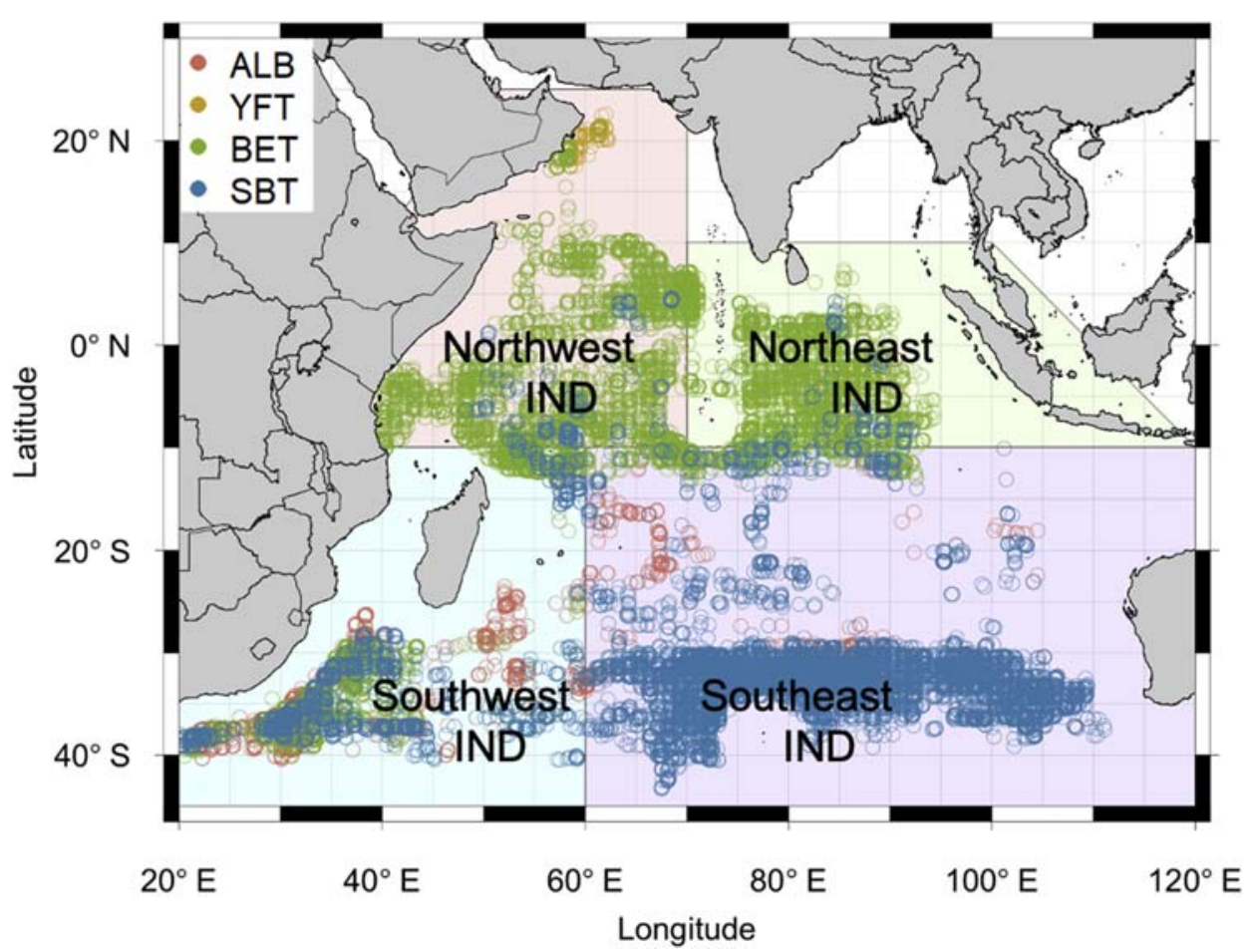

Fig. 1. Area stratification used in this study based on Taiwanese large-scale tuna longline effort distribution and targeted species as recorded by observers $(A L B=$ albacore; YFT = yellowfin tuna; BET = bigeye tuna; $S B T=$ southern bluefin tuna $)$.

A stepwise method was adopted to choose the best-fit model based on the Akaike information criterion (AIC) [44] and Bayes information criterion (BIC) [45]. A decrease in AIC or BIC indicated a better fit for the ZINB model. The best model was then used in subsequent analysis. Kleiber and

Table 2. Zero catch and immature percentage of silky shark caught by Taiwanese large-scale tuna longline vessels in the Indian Ocean from 2005 to 2019.

\begin{tabular}{|c|c|c|c|c|}
\hline \multirow[t]{3}{*}{ Year } & \multicolumn{2}{|c|}{ Zero catch percentage } & \multirow{2}{*}{\multicolumn{2}{|c|}{$\begin{array}{l}\begin{array}{l}\text { Immature } \\
\text { percentage }\end{array} \\
\text { Observer data }\end{array}$}} \\
\hline & \multirow{2}{*}{$\begin{array}{l}\text { Logbook } \\
\text { data }\end{array}$} & \multirow{2}{*}{$\begin{array}{l}\text { Observer } \\
\text { data }\end{array}$} & & \\
\hline & & & Female & Male \\
\hline 2005 & 94.49 & 98.31 & 42.86 & 33.33 \\
\hline 2006 & 97.22 & 87.98 & 73.08 & 65.63 \\
\hline 2007 & 97.59 & 88.53 & 57.14 & 52.80 \\
\hline 2008 & 97.02 & 94.55 & 65.22 & 46.51 \\
\hline 2009 & 95.69 & 95.24 & 87.80 & 87.04 \\
\hline 2010 & 96.97 & 94.50 & 92.11 & 83.13 \\
\hline 2011 & 97.60 & 97.51 & 100.00 & 84.62 \\
\hline 2012 & 95.97 & 96.84 & 62.50 & 92.31 \\
\hline 2013 & 94.67 & 99.75 & 91.30 & 80.00 \\
\hline 2014 & 93.74 & 100.00 & 93.75 & 92.86 \\
\hline 2015 & 99.57 & 99.36 & 88.89 & 80.00 \\
\hline 2016 & 97.52 & 98.63 & 96.08 & 89.80 \\
\hline 2017 & 95.72 & 99.79 & 100.00 & 84.21 \\
\hline 2018 & 92.61 & 98.91 & 89.29 & 50.00 \\
\hline 2019 & 88.68 & 99.62 & 94.39 & 91.46 \\
\hline Average & $95.67 \%$ & $96.63 \%$ & $82.29 \%$ & $74.25 \%$ \\
\hline
\end{tabular}

Zeileis [46] proposed using rootograms for model diagnostics to improve the assessment of the fit of a count regression model. We therefore examined our model through a residual analysis using the rootogram function in the R software package "countreg" [47].

The yearly standardized CPUE series was derived by using the adjusted means (i.e., least squared means) of the year effect parameters. The confidence intervals of the standardized CPUE were calculated by using a bootstrap resampling method based on the best model. The number of bootstrap subsamples was determined by the CPUE sample size each year (Table 1). The $95 \%$ confidence intervals for each year were computed by using a biascorrected percentile method with 10,000 replicates [48]. The statistical analysis and plotting in this study were performed using $\mathrm{R}$ 3.6. [47]. Cluster analysis was computed using the "kmeans" and "hclust" functions in the R software. ZINB models were implemented by using the "zeroinfl" function of the "pscl" package.

\section{Results}

\subsection{Sex and length distribution}

Spatial differences in the catch and CPUE between logbooks and observer records are displayed 
(a)
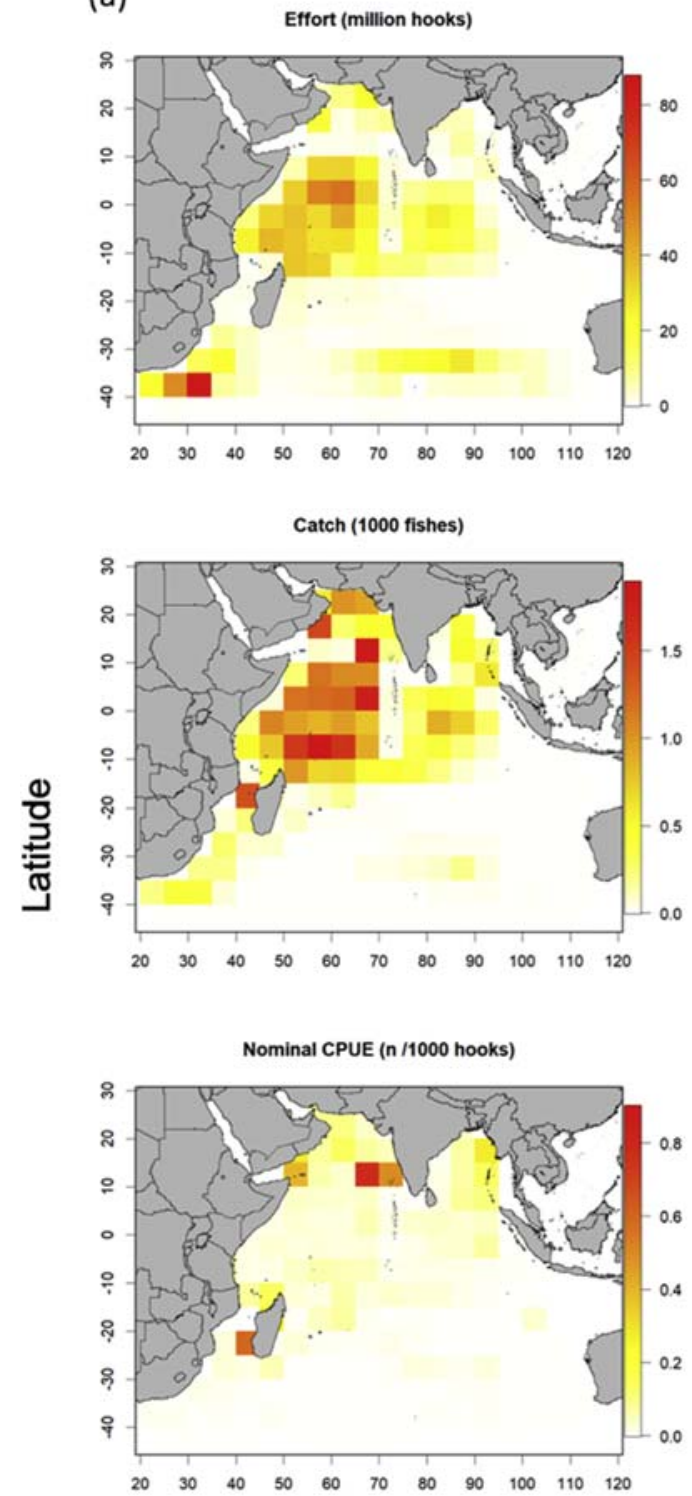

(b)
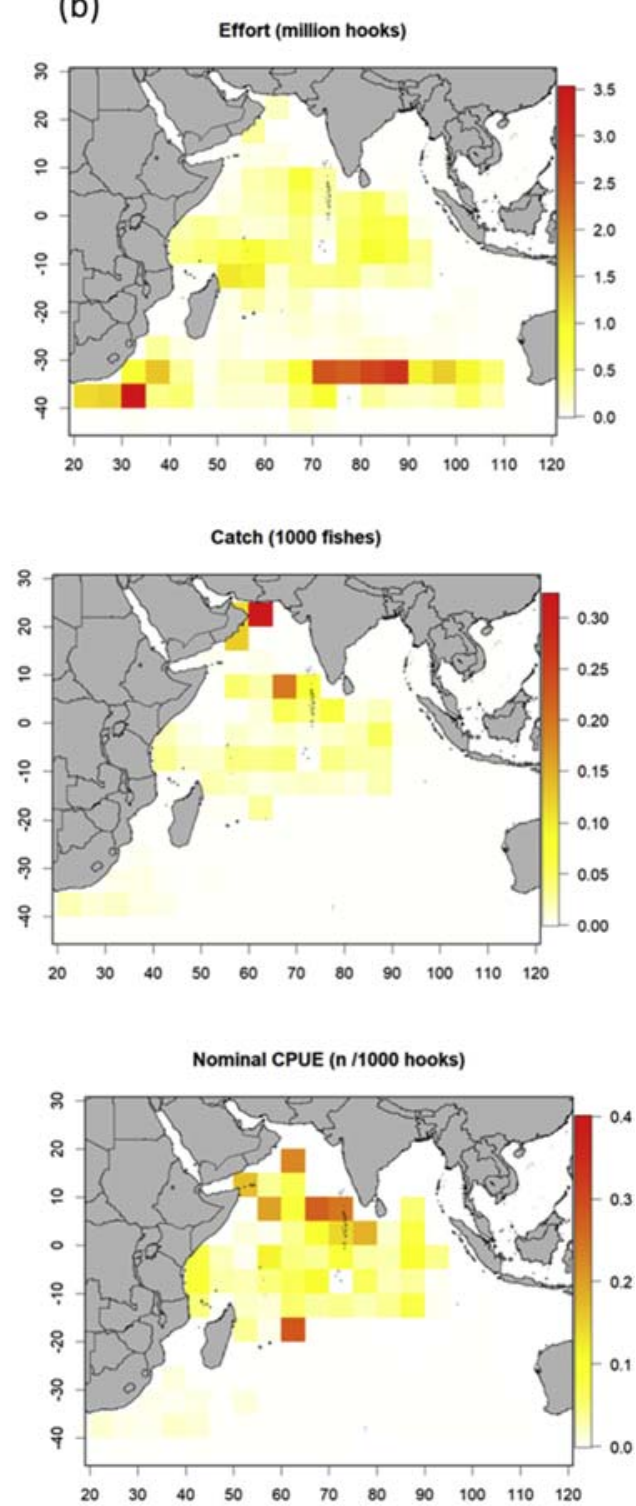

\section{Latitude $\left({ }^{\circ} \mathrm{E}\right)$}

Fig. 2. Silky shark catches, effort, and nominal CPUE distribution of Taiwanese large-scale tuna longline vessels recorded by logbook (a) and observer data (b) in the Indian Ocean from 2005 to 2019.

in Fig. 2. The logbook data had better spatial coverage than the observer data sets. Logbook data revealed the fishing distribution of Taiwanese LTLL vessels operating between $25^{\circ} \mathrm{N}$ and $45^{\circ} \mathrm{S}$ in the Indian Ocean from 2005 to 2019 (Fig. 2). The highest concentration of fishing effort occurred in equatorial areas $\left(20^{\circ} \mathrm{N}-20^{\circ} \mathrm{S}\right)$, whereas the highest number of silky shark catches occurred in the Northwest Indian Ocean (Fig. 2). The nominal CPUE indicated that the silky shark was spatially distributed in the north and southwest Indian Ocean. In the Southwest Indian Ocean, high catch frequency occurred throughout the year.
A total of 1591 silky shark specimens (799 females and 792 males) were recorded by onboard fishery observers (Fig. 3). FL ranged from 52 to $332 \mathrm{~cm}$; most females were $120-170 \mathrm{~cm}$ and most males were 120-178 cm (Fig. 4). Average annual immaturity for females and males was $82.29 \%$ and $74.25 \%$, respectively (Table 2). Despite a high proportion of immature individuals, a clear trend in the size distribution of the silky shark was not observed during the study period (Fig. 5). Additionally, no clear sex segregation was observed (Fig. 6). The sex ratio deviated from $1: 1$ between $20^{\circ} \mathrm{N}$ and $20^{\circ} \mathrm{S}$, and a significant difference was observed in sex ratios for 

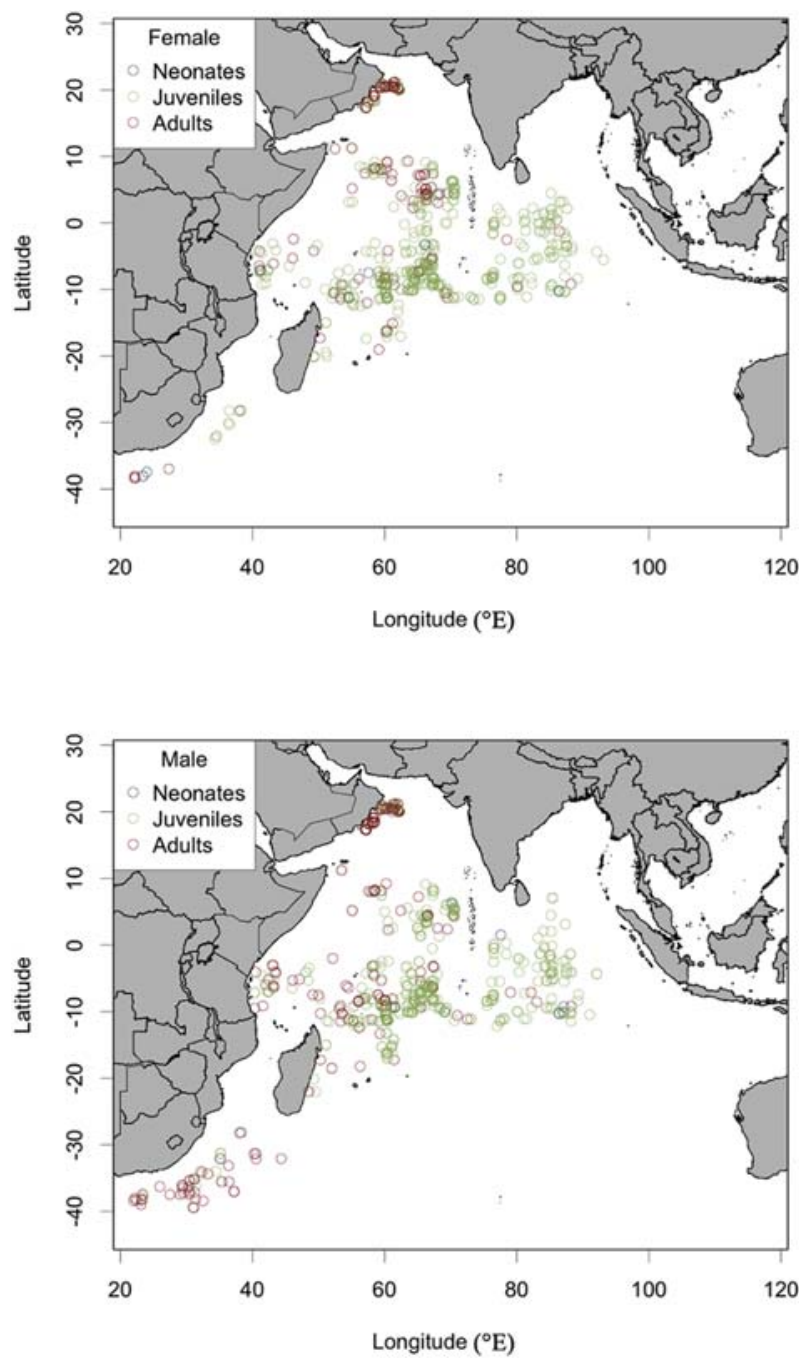

Fig. 3. Distribution of female and male silky sharks by life stage in the Indian Ocean as recorded by observers.

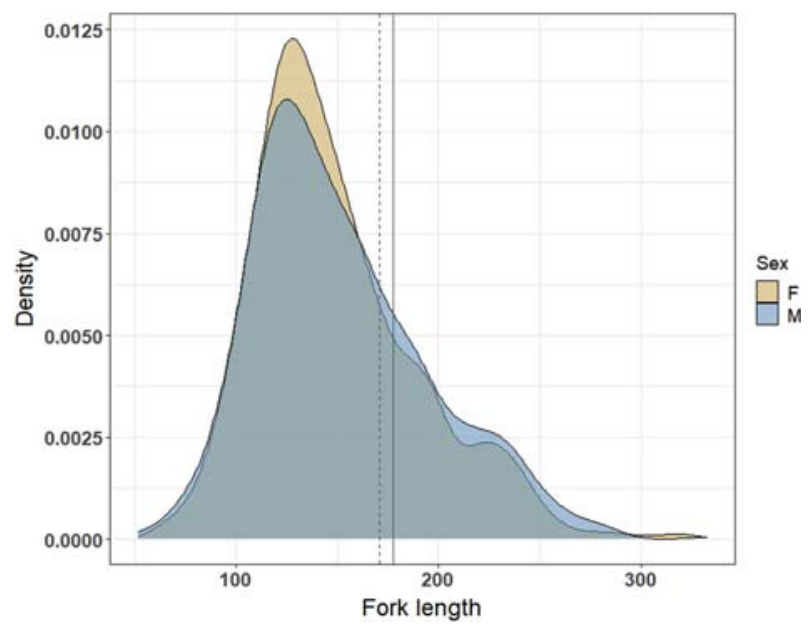

Fig. 4. Size frequency distribution of male and female silky sharks recorded by observers in the Indian Ocean. Vertical lines represent median size at maturity (solid line: female; dashed line: male). sharks in the south Indian Ocean (Fig. 6; chi-square: 23.9, $d f=3, p<0.001$ ).

\subsection{Cluster analysis}

Due to the numerous data sets contained in the logbooks, two-step cluster analysis was necessary to classify the data sets according to target species and fishing strategy. Cluster analysis was used to group the data into five distinct fishing clusters according to the percentage of target species (Fig. 7). Table 3 displays the species composition of each cluster: Cluster 1: Other fishes (OTH); Cluster 2: Yellowfin tuna (YFT); Cluster 3: Bigeye tuna (BET); Cluster 4: Albacore (ALB); Cluster 5: bigeye tuna (BET) and other fishes (OTH). Cluster 2 decreased during the study period, whereas Cluster 4 increased from 2008 onward (Fig. 8).

\subsection{CPUE standardization}

ZINB was applied to standardize the CPUE. The best model was selected according to the AIC and BIC. The best-fit model of ZINB was the model with the lowest $\operatorname{AIC}(234,536)$ and $\operatorname{BIC}(235,170)$ values. This model incorporated all effects. The AIC and BIC values used for model selection are displayed in Table 4. $\triangle \mathrm{AIC}$ and $\triangle \mathrm{BIC}$ indicated the reduction in the absolute value of AIC and BIC between the bestfit ZINB model and each other scenario. All variables were statistically significant. The most influential effect was year, followed by area. The smallest effect was observed for quarter. The annual standardized CPUE and nominal CPUE values are displayed with $95 \%$ confidence intervals in Fig. 9 and Table 5. Similar trends were observed: a steady rise between 2011 and 2014, a sharp decrease in 2015, and then a rapid increase from 2016 to 2019. The residual plots indicated that the ZINB models had an excellent fit with the bycatch data (Fig. 10).

\section{Discussion}

\subsection{Distribution patterns}

The silky shark has a variety of habitats and is often captured on the continental shelf and in the open ocean. The shark prefers waters above $23{ }^{\circ} \mathrm{C}$ [17]. The majority of silky sharks observed in this study were captured in the north and northwestern Indian Ocean between $20^{\circ} \mathrm{N}$ and $20^{\circ} \mathrm{S}$ and had a high rate of both female and male immature individuals. Previous studies have indicated that the silky shark exhibits some size segregation $[18,49]$. Newborns and young juveniles are demersal, 


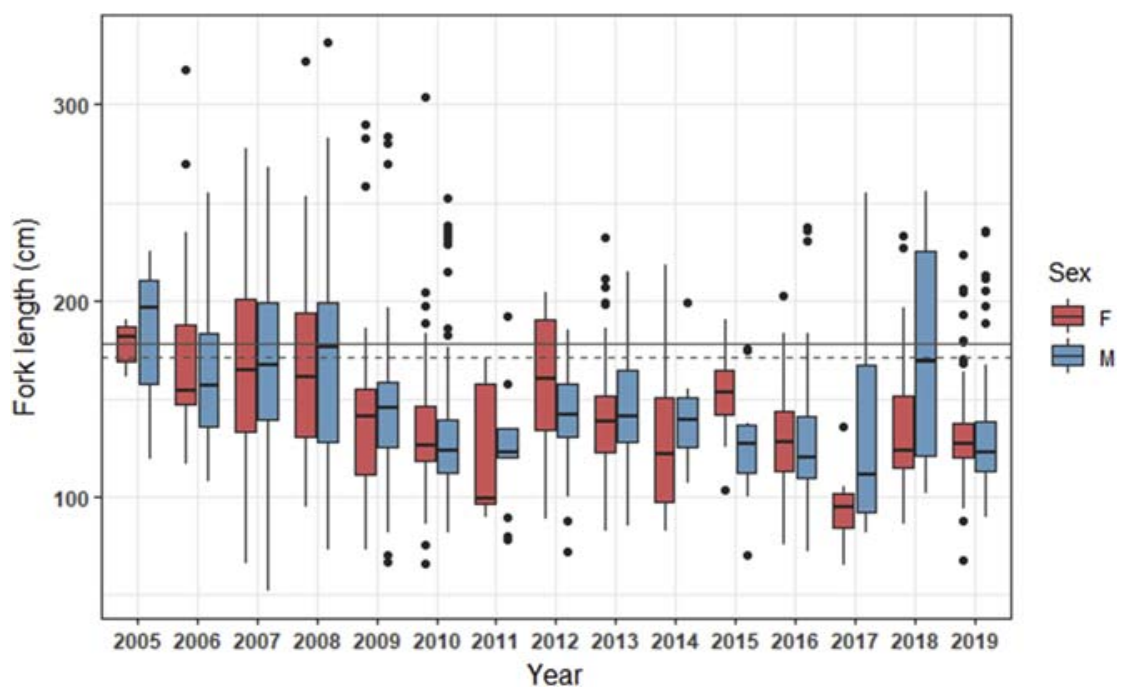

Fig. 5. Size distribution of silky sharks in the Indian Ocean by year from 2005 to 2019. Horizontal lines represent median size at maturity (solid lines: female; dashed lines: male).

tending to stay in shelf water nursery areas and deeper parts of the continental and insular shelves, whereas adults are pelagic, moving beyond the continental shelf and returning to shelf waters seasonally to feed and reproduce [50,51].

A high rate of immaturity was observed across our study area. Except for male samples in 2018, average body size decreased steadily from 2012 to 2019. Hutchinson [52] indicated that numerous juveniles ( $<190 \mathrm{~cm}$ Total Length) and adults caught by tuna and billfish fisheries were captured at higher latitudes $[11,53,54]$, which is consistent with our findings. However, no clear size segregation was observed in our study. The lack of size segregation may be due to our relatively small sample size from

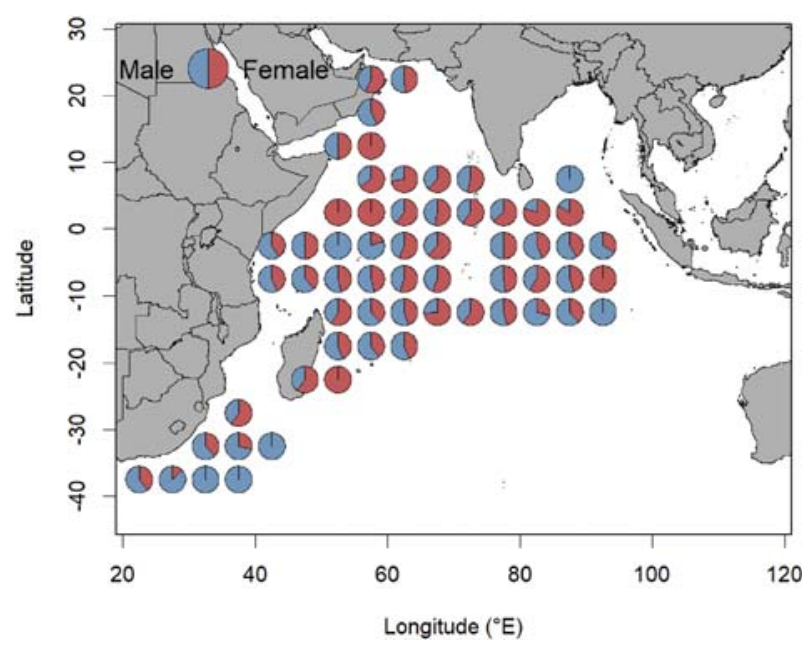

Fig. 6. Sex ratio distribution of silky sharks in the Indian Ocean from 2005 to 2019. observer data or due to different gear selection or bait types in the areas observed [55]. Data from a longer time series and broader geographical coverage are necessary to understand the reason for this discrepancy.

Larger silky shark specimens of both sexes were found in the southern Indian Ocean, whereas smaller specimens were more frequently observed in tropical and temperate areas. The seasonal movement of the silky shark has been documented. For example, in the Pacific Ocean, Strasburg [11] demonstrated that silky sharks tend to move from the equator toward higher latitudes in summer. In the Indian Ocean, numerous silky sharks were

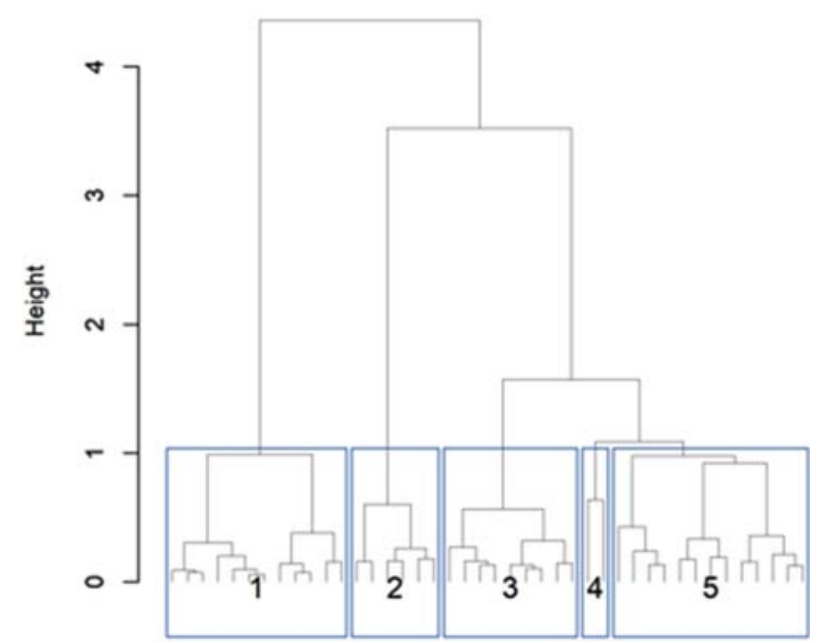

Fig. 7. Dendrogram of 42 nonhierarchical clusters for 499,981 longline sets of the Taiwanese large-scale tuna longline fishery in the Indian Ocean from 2005 to 2019. 
Table 3. Species composition percentage of each cluster from the Taiwanese large-scale tuna longline fishery in the Indian Ocean (2005-2019).

\begin{tabular}{|c|c|c|c|c|c|c|}
\hline \multirow[t]{2}{*}{ Species group } & & \multicolumn{5}{|l|}{ Cluster } \\
\hline & & 1 & 2 & 3 & 4 & 5 \\
\hline Albacore (ALB) & Thunnus alalunga & 9.71 & 1.63 & 8.17 & 56.87 & 13.61 \\
\hline Bigeye tuna (BET) & T. obesus & 6.53 & 20.30 & 39.88 & 6.49 & 19.76 \\
\hline Yellowfin tuna (YFT) & T. albacares & 2.64 & 56.48 & 21.24 & 3.17 & 10.67 \\
\hline Southern bluefin tuna (SBT) & T. maccoyii & 0.93 & 0.02 & 0.37 & 3.86 & 1.04 \\
\hline Swordfish (SWO) & Xiphias gladius & 1.46 & 3.81 & 4.95 & 1.52 & 3.09 \\
\hline Shark & & 1.77 & 2.09 & 3.83 & 1.94 & 3.31 \\
\hline Others & & 76.96 & 15.68 & 21.57 & 26.15 & 48.51 \\
\hline number of sets & & 180,016 & 73,267 & 145,148 & 15,561 & 85,968 \\
\hline$\%$ of Sets & & 36.01 & 14.65 & 29.03 & 3.11 & 17.19 \\
\hline
\end{tabular}

observed in the Gulf of Aden during the late spring and summer [56]. Additionally, a tagging study of the silky shark indicated sexual segregation and distinct habitat usage among individuals [55]. In our study, a larger number of males were captured in the southwestern Indian Ocean than females were. Neither logbook nor observer data were available for the southeastern Indian Ocean where Bonfil [56] found silky shark in great abundance. Additional research aiming to refine estimates of abundance and to ascertain movement patterns would
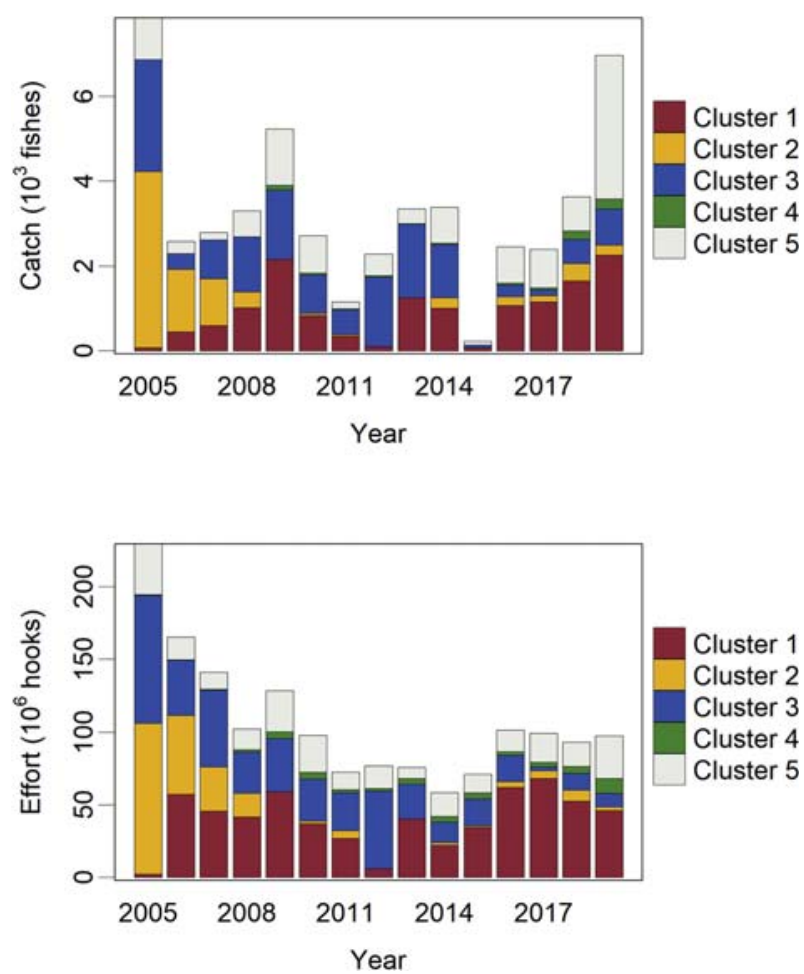

Fig. 8. Annual catch and effort distribution of the five clusters reflecting the targeting strategy of the Taiwanese large-scale tuna longline fleet from 2005 to 2019. Cluster 1: Other fishes (OTH); Cluster 2: Yellowfin tuna (YFT); Cluster 3: Bigeye tuna (BET); Cluster 4: Albacore (ALB); and Cluster 5: Bigeye tuna (BET) and other fishes (OTH). considerably improve the understanding of silky shark population dynamics in the Indian Ocean.

\subsection{CPUE standardization}

The logbook and observer data provided valuable spatiotemporal information related to fishing activities. Because logbook data have wider coverage than observer data, the CPUE of the silky shark was standardized based on the logbook data. To ensure that CPUE is proportional to abundance, possible confounding factors must be removed. A variety of methods are available for this task. In a study of oceanic whitetip shark bycatch of the Hawaiian pelagic longline fishery, Brodziak and Walsh [57] applied five different standardization models: Poisson, negative binomial, zero-inflated Poisson, ZINB, and delta-gamma. The results indicated that a zeroinflated model is more suitable when the zero catch rate of shark is high. Due to insufficient catch process information and a large observed zero catch rate, the ZINB model was deemed appropriate for this study.

Although delta models have also been widely applied for CPUE standardization of nontarget species with high zero catch rates [36], these models were not used in our study because zero-valued observations may be incorrectly pooled [29]. In this

Table 4. Deviance table for the ZINB model of the silky shark in the Indian Ocean. The absolute value of the AIC and BIC for the null model was 246,223 and 236,190 , respectively.

\begin{tabular}{lllllll}
\hline \multicolumn{7}{l}{ Zero-inflated negative binomial } \\
\hline Source & Df & Chisq & $\operatorname{Pr}(>$ Chisq $)$ & $\Delta$ BIC & $\Delta$ AIC & \\
\hline Year & 14 & 689.369 & $<2.2 \mathrm{e}-16$ & -6113.5 & -6424.9 & $* * *$ \\
Quarter & 3 & 91.594 & $<2.2 \mathrm{e}-16$ & -98.9 & -165.6 & $* * *$ \\
Area & 3 & 65.137 & $4.69 \mathrm{E}-14$ & -2467.2 & -2533.9 & $* * *$ \\
Cluster & 4 & 132.723 & $<2.2 \mathrm{e}-16$ & -498 & -586.9 & $* * *$ \\
NHBF & 1 & 103.583 & $<2.2 \mathrm{e}-16$ & -403.3 & -425.5 & $* * *$ \\
Vessel & 2 & 14.441 & 0.0007316 & -359.4 & -403.8 & $* * *$ \\
\hline Signif.
\end{tabular}

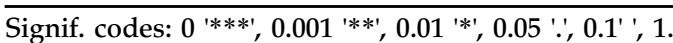




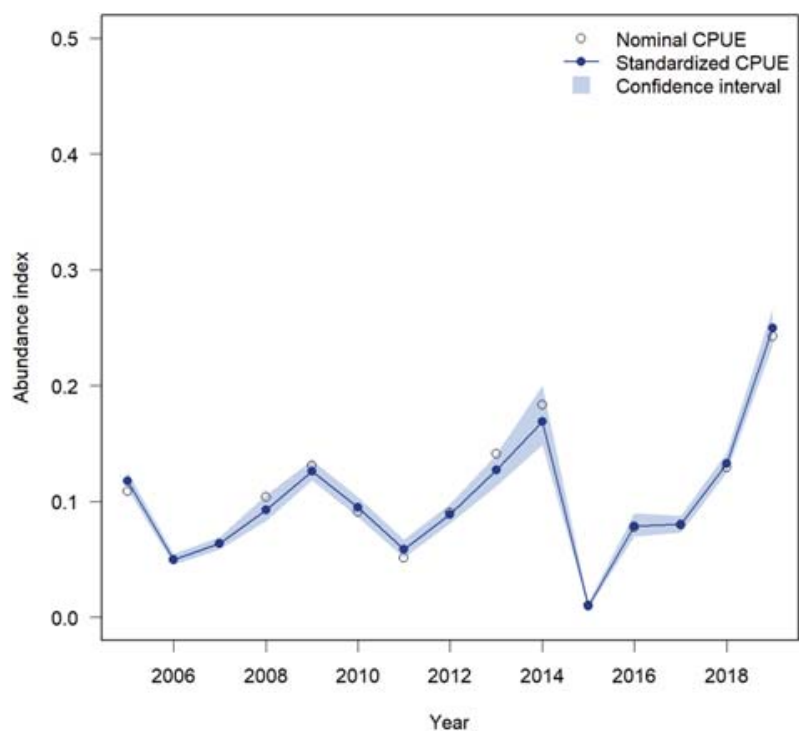

Fig. 9. Nominal and standardized CPUEs (per 1000 hooks) with $95 \%$ confidence interval for a ZINB model of silky shark abundance.

study, year was observed to have the most significant influence and thus was the most important factor. However, no clear difference was observed between nominal and standardized CPUE. The lack of difference may be due to the small number of years in the data sets and the lack of a homogeneous fishing strategy distribution both spatially and temporally [58].

Recent studies [59-62] have suggested that spatiotemporal models (e.g., the vector autoregressive spatiotemporal model) may yield more precise, biologically reasonable, and interpretable estimates of abundance than conventional methods such as generalized linear models (GLMs) or deltageneralized linear mixed models. Although these models may reduce bias associated with sample selection and fill in spatial gaps associated with fishery-dependent data $[63,64]$, the model configurations and results of such sophisticated methods are complex and may be difficult to understand [61]. The simple ZINB model adopted in this study generates results that are easily interpreted and understood.

Longline fisheries often adopt different strategies for different target species. Strategic changes include different hook size, gear, operational time, location, and depth. When this detailed information is not available or recorded, cluster analysis is useful to separate the data into different groups based on target species [65]. Our results indicate that cluster was an important factor explaining the variance of ZINB models. Our integrated approach can be used to understand the fishery strategies for other shark species and to derive relative abundance indices for stock assessment and management.

\subsection{Stock status in the Indian Ocean}

Little research has been conducted on the CPUE of the silky shark in the Indian Ocean. Two studies in the eastern Indian Ocean (the main operational area of the Indonesian fishery) [66,67] calculated relative abundance indices of the silky shark by using a GLM to estimate the standardized CPUE. Jatmiko [66] analyzed observer data for the Indonesian longline fleet from 2006 to 2017, and Simeon [67] conducted research investigating two fishing ports from 2015 to 2016. Simeon's study [67] indicated that the silky shark population increased between 2015 and 2016. However, the study also demonstrated higher juvenile mortality associated with smaller fishing vessels operating in coastal

Table 5. Estimated nominal and standardized CPUE (per 1000 hooks) of the ZINB for silky shark caught by the Taiwanese large-scale tuna longline fishery in the Indian Ocean.

\begin{tabular}{|c|c|c|c|c|c|c|c|}
\hline \multirow[t]{2}{*}{ Year } & \multicolumn{2}{|c|}{ Original Values } & \multicolumn{5}{|c|}{ Bias-corrected bootstrap confidence intervals } \\
\hline & Nominal & Standardized & Lower CI & Upper CI & Mean & STD & $\mathrm{CV}$ \\
\hline 2005 & 0.11139 & 0.11825 & 0.11047 & 0.11127 & 0.13452 & 0.00669 & 0.04975 \\
\hline 2006 & 0.05171 & 0.05043 & 0.04446 & 0.05281 & 0.05441 & 0.00338 & 0.06209 \\
\hline 2007 & 0.05591 & 0.05440 & 0.04557 & 0.06153 & 0.05585 & 0.00413 & 0.07388 \\
\hline 2008 & 0.10776 & 0.09849 & 0.09408 & 0.09547 & 0.11814 & 0.00975 & 0.08251 \\
\hline 2009 & 0.11097 & 0.10731 & 0.09919 & 0.11948 & 0.10495 & 0.00557 & 0.05308 \\
\hline 2010 & 0.06202 & 0.06489 & 0.06052 & 0.06302 & 0.07479 & 0.00470 & 0.06291 \\
\hline 2011 & 0.04645 & 0.05465 & 0.04681 & 0.05829 & 0.05949 & 0.00460 & 0.07726 \\
\hline 2012 & 0.08761 & 0.08878 & 0.07773 & 0.09786 & 0.08973 & 0.00509 & 0.05675 \\
\hline 2013 & 0.14505 & 0.13510 & 0.13537 & 0.14061 & 0.12172 & 0.00627 & 0.05153 \\
\hline 2014 & 0.18423 & 0.17042 & 0.15960 & 0.20791 & 0.15746 & 0.01268 & 0.08051 \\
\hline 2015 & 0.00990 & 0.00915 & 0.00774 & 0.01194 & 0.00820 & 0.00113 & 0.13774 \\
\hline 2016 & 0.08182 & 0.08056 & 0.06864 & 0.09451 & 0.08038 & 0.00658 & 0.08184 \\
\hline 2017 & 0.08325 & 0.08367 & 0.07635 & 0.09393 & 0.08297 & 0.00435 & 0.05248 \\
\hline 2018 & 0.12764 & 0.12909 & 0.12277 & 0.14180 & 0.12653 & 0.00449 & 0.03546 \\
\hline 2019 & 0.23153 & 0.24614 & 0.24681 & 0.25240 & 0.22976 & 0.00735 & 0.03200 \\
\hline
\end{tabular}




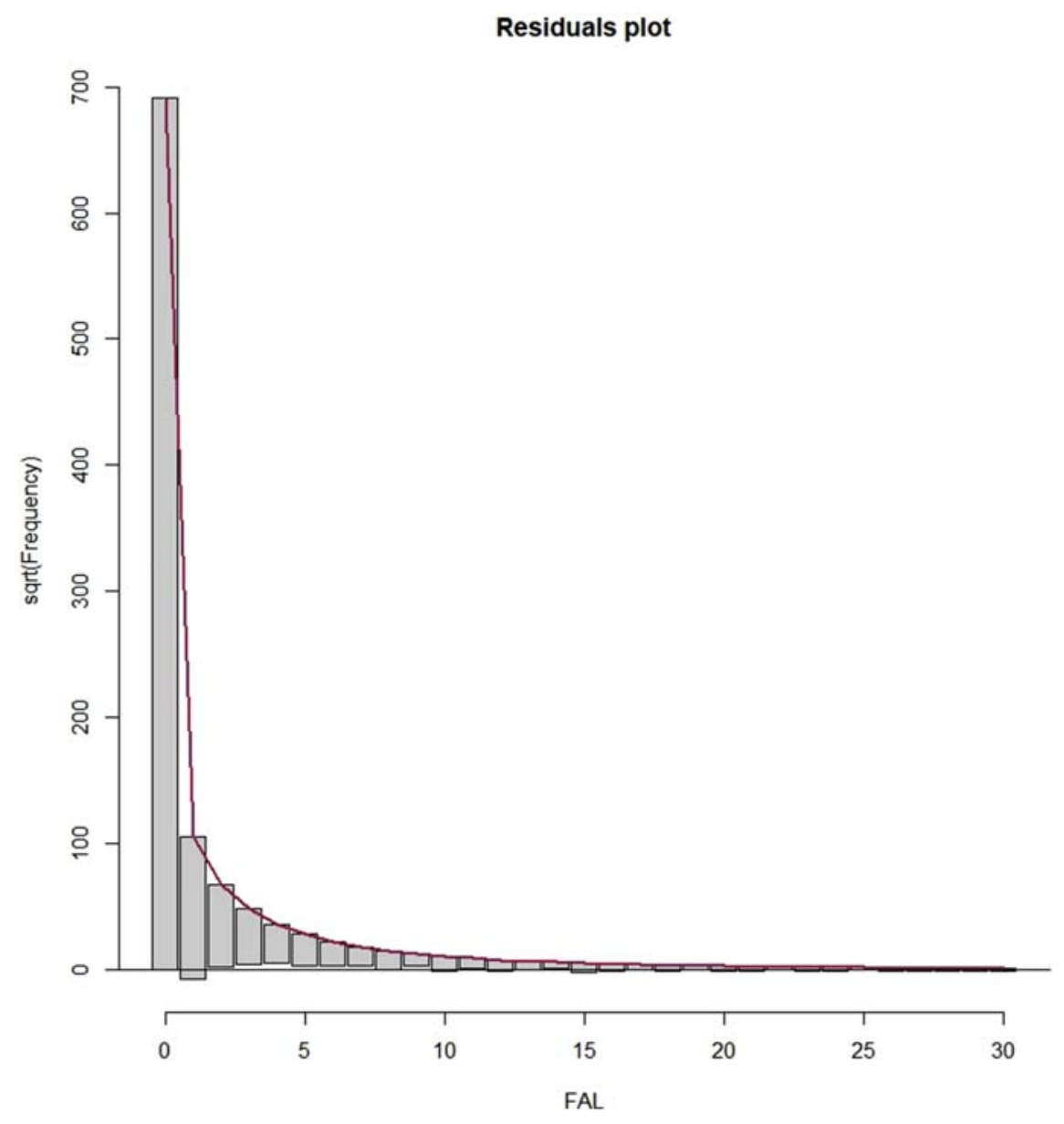

Fig. 10. Rootogram residuals plot for the ZINB model fit to the silky shark logbook data.

areas. These two studies notwithstanding, detailed information is insufficient, and therefore, stock assessments of the silky shark in the Indian Ocean remain uncertain.

By using data from the Taiwanese large-scale longline fishery from 2005 to 2019, this study is the first to investigate the population abundance of the silky shark across the entire Indian Ocean. The catch number was observed to decrease from 2008 to 2012 (lowest value in 2015) but then increase to a maximum in 2019 (Fig. 9). In the southwestern Indian Ocean, high catches of silky sharks were frequent throughout the year, with silky sharks caught as bycatch by LTLL targeting oilfish (Ruvettus pretiosus) and escolar (Lepidocybium flavobrunneum). Because catches of both silky shark and other species (primarily oilfish and escolars) were lower in 2015 than in other years, the low catches of silky sharks in $\mathbf{2 0 1 5}$ may be due to particularly low fishing effort in the southwestern Indian Ocean. However, these results may reflect only partial stock status because our spatial coverage may be insufficient to judge the entire stock status. Additionally, only commercial fishing records were used to calculate relative abundance indices in this study. Although the indices were derived by using standardized procedures, fishery-independent data, such as survey data, would be more accurate because there would be no catch bias due to discard, release, or nonreporting, which are typical occurrences for bycatch species such as sharks. Further fishery-independent studies are necessary to better evaluate the status, ecology, and distribution of the silky shark in the Indian Ocean. For future management of the silky shark, Tsai [27] suggested that sex-specific and immature shark protection strategies are the most efficient conservation method. Because global shark catches and landings are increasing, the monitoring of silky shark populations is necessary to ensure the protection of this species in the Indian Ocean.

\section{Conflicts of interest}

The named authors have no conflict of interest, financial or otherwise. 


\section{Acknowledgments}

The authors thank the Overseas Fisheries Development Council, Taiwan for providing shark catch and effort data of longline fisheries. We also thank anonymous reviewers for their helpful comments, which greatly improved this manuscript. This study was financially supported by the Fisheries Agency of Council of Agriculture of Taiwan under Contract No. 108AS-9.1.2-FA-F2 and 109AS-9.1.2-FA-F2. This manuscript was edited by Wallace Academic Editing.

\section{References}

[1] Ferretti F, Worm B, Britten GL, Heithaus MR, Lotze HK. Patterns and ecosystem consequences of shark declines in the ocean. Ecol Lett 2010;13(8):1055-71.

[2] Stevens J, Bonfil R, Dulvy N, Walker P. The effects of fishing on sharks, rays, and chimaeras (chondrichthyans), and the implications for marine ecosystems. ICES (Int Counc Explor Sea) J Mar Sci 2000;57(3):476-94.

[3] Heithaus MR, Frid A, Vaudo JJ, Worm B, Wirsing AJ. Unraveling the ecological importance of elasmobranchs. Sharks and their relatives II. CRC Press; 2010. p. 627-54.

[4] Barker MJ, Schluessel V. Managing global shark fisheries: suggestions for prioritizing management strategies. Aquat Conserv Mar Freshw Ecosyst 2005;15(4):325-47.

[5] Jordán F, Scheuring I, Vida G. Species positions and extinction dynamics in simple food webs. J Theor Biol 2002; 215(4):441-8.

[6] Myers RA, Baum JK, Shepherd TD, Powers SP, Peterson CH. Cascading effects of the loss of apex predatory sharks from a coastal ocean. Science 2007;315(5820):1846-50.

[7] Baum JK, Worm B. Cascading top-down effects of changing oceanic predator abundances. J Anim Ecol 2009;78(4): 699-714.

[8] Navia AF, Cortés E, Mejía-Falla PA. Topological analysis of the ecological importance of elasmobranch fishes: a food web study on the Gulf of Tortugas, Colombia. Ecol Model 2010;221(24):2918-26.

[9] Bornatowski H, Braga R, Abilhoa V, Corrêa M. Feeding ecology and trophic comparisons of six shark species in a coastal ecosystem off southern Brazil. J Fish Biol 2014;85(2):246-63.

[10] Casini M, Hjelm J, Molinero J-C, Lövgren J, Cardinale M, Bartolino V, et al. Trophic cascades promote threshold-like shifts in pelagic marine ecosystems. Proc Natl Acad Sci Unit States Am 2009;106(1):197-202.

[11] Strasburg DW. Distribution, abundance, and habits of pelagic sharks in the central Pacific Ocean. Fisheries 1958;1:2S.

[12] Cortés E. Life history patterns and correlations in sharks. Rev Fish Sci 2000;8(4):299-344.

[13] García VB, Lucifora LO, Myers RA. The importance of habitat and life history to extinction risk in sharks, skates, rays and chimaeras. Proc Biol Sci 2008;275(1630):83-9.

[14] Dulvy NK, Fowler SL, Musick JA, Cavanagh RD, Kyne PM, Harrison LR, et al. Extinction risk and conservation of the world's sharks and rays. elife 2014;3:e00590.

[15] Dulvy NK, Baum JK, Clarke S, Compagno LJ, Cortés E, Domingo A, et al. You can swim but you can't hide: the global status and conservation of oceanic pelagic sharks and rays. Aquat Conserv Mar Freshw Ecosyst 2008;18(5):459-82.

[16] Castro JI, Woodley CM, Brudek RL. A preliminary evaluation of the status of shark species. Food \& Agriculture Org.; 1999.

[17] Last PR, Stevens JD, Swainston R, Davis G. Sharks and rays of Australia. 2009.

[18] Joung S-J, Chen C-T, Lee H-H, Liu K-M. Age, growth, and reproduction of silky sharks, Carcharhinus falciformis, in northeastern Taiwan waters. Fish Res 2008;90(1-3):78-85.
[19] Matsunaga H, Nakano H. Species composition and CPUE of pelagic sharks caught by Japanese longline research and training vessels in the Pacific Ocean. Fish Sci 1999;65(1): $16-22$.

[20] Oliver S, Braccini M, Newman SJ, Harvey ES. Global patterns in the bycatch of sharks and rays. Mar Pol 2015;54: 86-97.

[21] Stock status of the silky shark in the eastern Pacific Ocean. In: Aires-da-Silva A, Lennert-Cody C, Maunder M, editors. 4th meeting of the IATTC scientific advisory meeting; 2013.

[22] Baum JK, Myers RA. Shifting baselines and the decline of pelagic sharks in the Gulf of Mexico. Ecol Lett 2004;7(2): 135-45.

[23] Rice J, Harley S. Updated stock assessment of silky sharks in the western and central Pacific Ocean. Scient Commit Ninth Reg Sess 2013:6-14.

[24] Rigby C, Sherman C, Chin A, Simpfendorfer C. Carcharhinus falciformis. The IUCN red list of threatened species 2017: e. T39370A117721799. 2019.

[25] CITES Animals Committee. Conservation and management of sharks and stingrays: other animals committee tasks related to conservation and management of sharks. Seventeenth meeting of the conference of the parties bangkok (South Africa) from 24 september to 5 october 2016. 2016.

[26] de Urbina JO, Brunel T, Coelho R, Merino G, Rosa D, Santos C, et al. A preliminary stock assessment for the silky shark in the Indian ocean using a data-limited approach. Seychelles: IOTC; 2018.

[27] Tsai W-P, Wang Y-J, Yamaguchi A. Demographic analyses of the data limited silky shark population in the Indian Ocean using a two-sex stochastic matrix framework. J Mar Sci Technol 2019;27(1):55-63.

[28] Maunder MN, Punt AE. Standardizing catch and effort data: a review of recent approaches. Fish Res 2004;70(2-3):141-59.

[29] Minami M, Lennert-Cody CE, Gao W, Román-Verdesoto M. Modeling shark bycatch: the zero-inflated negative binomial regression model with smoothing. Fish Res 2007;84(2): 210-21.

[30] Lo NC-h, Jacobson LD, Squire JL. Indices of relative abundance from fish spotter data based on delta-lognornial models. Can J Fish Aquat Sci 1992;49(12):2515-26.

[31] Lambert D. Zero-inflated Poisson regression, with an application to defects in manufacturing. Technometrics 1992;34(1): $1-14$.

[32] Welsh AH, Cunningham RB, Donnelly C, Lindenmayer DB. Modelling the abundance of rare species: statistical models for counts with extra zeros. Ecol Model 1996;88(1-3): 297-308.

[33] Dunn A, Harley S, Doonan I, Bull B. Calculation and interpretation of catch-per-uniteffort (CPUE) indices. New Zealand Fisher Assess Report 2000;1:44.

[34] Harley SJ, Myers RA, Dunn A. Is catch-per-unit-effort proportional to abundance? Can J Fish Aquat Sci 2001;58(9): 1760-72.

[35] Hinton MG, Maunder MN. Methods for standardizing CPUE and how to select among them. Col Vol Sci Pap ICCAT 2004; 56(1):169-77.

[36] Tsai W-P, Sun C-L, Liu K-M, Wang S-B, Lo NC. Cpue standardization and catch estimate of blue shark by Taiwanese large-scale tuna longline fishery in the north Pacific Ocean. J Mar Sci Technol 2015;23(4):567-74.

[37] He X, Bigelow KA, Boggs CH. Cluster analysis of longline sets and fishing strategies within the Hawaii-based fishery. Fish Res 1997;31(1-2):147-58.

[38] Hoyle S, Semba Y, Kai M, Okamoto H. Development of Southern Hemisphere porbeagle shark stock abundance indicators using Japanese commercial and survey data. New Zealand fisheries assessment report 2017;7.

[39] Yeh Y-M, Chang S-T. Updated CPUE standardizations for bigeye and yellowfin tuna caught by Taiwanese longline fishery in the Indian Ocean using generalized linear model. IOTC; 2015. WPTT17-25; 2015. 
[40] Hall N, Bartron C, White W, Potter I. Biology of the silky shark Carcharhinus falciformis (Carcharhinidae) in the eastern Indian Ocean, including an approach to estimating age when timing of parturition is not well defined. J Fish Biol 2012;80(5):1320-41.

[41] Tsai W-P, Liu K-M. Updated and revised standardized catch rate of Blue Sharks caught by the Taiwanese longline fishery in the Atlantic Ocean. In: ICCAT (International Commission for the Conservation of Atlantic Tunas) Collective Volume of Scientific Papers, 72; 2016. p. 1134-49.

[42] Johnson RA, Wichern DW. Applied multivariate statistical analysis. Upper Saddle River, NJ: Prentice-Hall; 2002.

[43] Wang S-P. CPUE standardization of blue marlin caught by Taiwanese large scale longline fishery in the Indian Ocean. IOTC; 2019. WPB17-18; 2019.

[44] Akaike H. Information theory and an extension of the maximum likelihood principle. Selected papers of hirotugu akaike. Springer; 1998. p. 199-213.

[45] Schwarz G. Estimating the dimension of a model. Ann Stat 1978;6(2):461-4.

[46] Kleiber C, Zeileis A. Visualizing count data regressions using rootograms. Am Statistician 2016;70(3):296-303.

[47] Team RCR. A language and environment for statistical computing. 2013.

[48] Efron B, Tibshirani RJ. An introduction to the bootstrap. CRC Press; 1994.

[49] Camhi MD, Pikitch E, Babcock EA. Sharks of the open ocean. America: Blackwell. 2008. p. 140-5.

[50] Bonfil R. Status of shark resources in the Southern Gulf of Mexico and Caribbean: implications for management. Fish Res 1997;29(2):101-17.

[51] Branstetter S. Age, growth and reproductive biology of the silky shark, Carcharhinus falciformis, and the scalloped hammerhead, Sphyrna lewini, from the northwestern Gulf of Mexico. Environ Biol Fish 1987;19(3):161-73.

[52] Hutchinson M, Coffey DM, Holland K, Itano D, Leroy B, Kohin S, et al. Movements and habitat use of juvenile silky sharks in the Pacific Ocean inform conservation strategies. Fish Res 2019;210:131-42.

[53] Bonfil R. The biology and ecology of the silky shark, Carcharhinus falciformis. Sharks of the open ocean: biology, fisheries and conservation. 2008. p. 114-27.

[54] Galván-Tirado C, Díaz-Jaimes P, García-de León FJ, GalvánMagaña F, Uribe-Alcocer M. Historical demography and genetic differentiation inferred from the mitochondrial DNA of the silky shark (Carcharhinus falciformis) in the Pacific Ocean. Fish Res 2013;147:36-46.

[55] Clarke C, Lea J, Ormond R. Reef-use and residency patterns of a baited population of silky sharks, Carcharhinus falciformis, in the Red Sea. Mar Freshw Res 2011;62(6):668-75.
[56] Bonfil R. Consultancy on elasmobranch identification and stock assessment in the red sea and Gulf of aden. Final report presented to the regional organization for the conservation of the environment of the red sea and Gulf of aden, jeddah. 2003. p. 195.

[57] Brodziak J, Walsh WA. Model selection and multimodel inference for standardizing catch rates of bycatch species: a case study of oceanic whitetip shark in the Hawaii-based longline fishery. Can J Fish Aquat Sci 2013;70(12):1723-40.

[58] Tolotti MT, Travassos P, Frédou FL, Wor C, Andrade HA, Hazin F. Size, distribution and catch rates of the oceanic whitetip shark caught by the Brazilian tuna longline fleet. Fish Res 2013;143:136-42.

[59] Kai M, Thorson JT, Piner KR, Maunder MN. Predicting the spatio-temporal distributions of pelagic sharks in the western and central North Pacific. Fish Oceanogr 2017;26(5): 569-82.

[60] Shelton AO, Thorson JT, Ward EJ, Feist BE. Spatial semiparametric models improve estimates of species abundance and distribution. Can J Fish Aquat Sci 2014;71(11) 1655-66.

[61] Thorson JT. Guidance for decisions using the Vector Autoregressive Spatio-Temporal (VAST) package in stock, ecosystem, habitat and climate assessments. Fish Res 2019; 210:143-61.

[62] Thorson JT, Shelton AO, Ward EJ, Skaug HJ. Geostatistical delta-generalized linear mixed models improve precision for estimated abundance indices for West Coast groundfishes. ICES (Int Counc Explor Sea) J Mar Sci 2015;72(5): 1297-310.

[63] Thorson JT, Fonner R, Haltuch MA, Ono K, Winker H. Accounting for spatiotemporal variation and Fisher targeting when estimating abundance from multispecies fishery data. Can J Fish Aquat Sci 2016;74(11):1794-807.

[64] Walter JF, Hoenig JM, Christman MC. Reducing bias and filling in spatial gaps in fishery-dependent catch-per-uniteffort data by geostatistical prediction, I. Methodology and simulation. N Am J Fish Manag 2014;34(6):1095-107.

[65] Carvalho FC, Murie DJ, Hazin FH, Hazin HG, LeiteMourato B, Travassos P, et al. Catch rates and size composition of blue sharks (Prionace glauca) caught by the Brazilian pelagic longline fleet in the southwestern Atlantic Ocean. Aquat Living Resour 2010;23(4):373-85.

[66] Jatmiko I, Setyadji B, Fahmi Z, Rochman F. Standardized cpue of silky shark (Carcharhinus falciformis) caught by Indonesian longline fleet in the Eastern indian ocean.

[67] Simeon BM, Muttaqin E, Mardhiah U, Ichsan M, Prasetyo AP, Yulianto I. Increasing abundance of silky sharks in the Eastern Indian Ocean: good news or a reason to be cautious? Fishes 2018;3(3):29. 